\title{
Evaluation of Alterations in Uterine Blood Flow using Doppler Ultrasonography in Pregnant, Genotyped Beef Cows and Heifers Consuming Endophyte-Infected Tall Fescue Seeds and Supplemented with Rumen-Protected Niacin
}

\author{
Gard Schnuelle $\mathbf{J}^{1}$, Blythe $\mathrm{EK}^{2}$, Cole $\mathbf{R}^{1}$, Taylor $\mathrm{S}^{1}$, Alfaro GF${ }^{3}$, Muntifering \\ $\mathrm{RB}^{3}$, Pacheco $\mathrm{WJ}^{4}$, Rodning $\mathrm{SP}^{3}$ and Moisa $\mathrm{SJ}^{3 *}$ \\ ${ }^{1}$ Department of Clinical Sciences, College of Veterinary Medicine, Auburn University, USA \\ ${ }^{2}$ College of Agriculture Research Office, Auburn University, USA \\ ${ }^{3}$ Department of Animal Science, Auburn University, USA \\ ${ }^{4}$ Department of Poultry Science, Auburn University, USA
}

Research Article

Volume 6 Issue 1

Received Date: March 04, 2021

Published Date: March 19, 2021

DOI: $10.23880 /$ oajvsr-16000207

*Corresponding author: Sonia J Moisá, Department of Animal Sciences, Auburn University, 361 Mell Street, Auburn, AL 368495426, USA, Tel: 334-844-4432; Fax: 334-844-1519; Email: sjm0044@auburn.edu

\section{Abstract}

Fescue toxicity is a nutritional-related disease generated in a forage-based beef herd exposed to ergot alkaloids (i.e. ergovaline) present in endophyte-infected tall fescue that produces important economic losses. The combination of a genetic test for susceptibility to fescue toxicity and supplementation with rumen-protected niacin could potentially reduce the toxic effects of ergovaline on beef cow and heifers' reproductive performance during mid-gestation by improving uterine blood flow. Our main objective was to use color Doppler ultrasonography to evaluate the occurrence of any alteration in uterine arterial blood flow in pregnant, genotyped beef cows and heifers exposed to endophyte-infected tall fescue seeds and supplemented with rumen-protected niacin. We hypothesize that genetically-tested susceptible control beef cows will have narrower uterine arteries and decrease blood flow as compared to tolerant cows that received rumen-protected niacin. Rumen-protected niacin was selected for this study due to its well-known effect as a vasodilator. Therefore, it might help cope with blood vessel constriction generated by ergovaline present in endophyte-infected tall fescue seeds. Results showed the negative effect of exposure to ergovaline in the uterine blood flow of pregnant beef cattle through an increase in the resistivity index. No Doppler parameters detected positive effects of genetic and nutritional treatments.

Keywords: Uterine Blood Flow; Doppler Ultrasonography; Genotyped Beef Cows; Endophyte-Infected Tall Fescue; RumenProtected Niacin

\section{Introduction}

Tall fescue [Lolium arundinaceum (Schreb.) Darbysh] is a widely adapted, cool season perennial grass present in over 14 million hectares in the Southeastern United States [1]. Most tall fescue plants are naturally infected with an endophyte, Epichloë coenophiala [2], which produces ergot alkaloids (e.g., ergovaline), known to induce fescue toxicity 


\section{Open Access Journal of Veterinary Science \& Research}

in livestock, causing adverse effects on their performance [3-5]. Economic losses associated with tall fescue toxicity have been estimated to be close to $\$ 3.5$ billion annually [6]. In order to mitigate these economic losses to benefit the forage-based livestock industry, we determined whether a combination of a genetic test for susceptibility to fescue toxicity and supplementation with rumen-protected niacin (RPN) could potentially reduce the toxic effects of ergovaline on beef cow and heifer reproductive performance during mid-gestation by improving uterine blood flow.

All ergot alkaloids, especially ergovaline, are vasoactive. Therefore, vasoconstriction can occur in peripheral vasculature of animals grazing fescue [7]. One of the most common fescue toxicity symptoms is associated with extremity vasoconstriction [8]. Furthermore, the results of a previous study indicated that a chronic exposure to ergot alkaloids from endophyte-infected tall fescue seed reduced ovarian and uterine vessel area, restricting blood flow to the reproductive organs [9]. To counteract this negative effect, rumen-protected niacin was selected for this study due to its well-known effect as a vasodilator; hence, we hypothesize that rumen-protected niacin might help to cope against blood vessel constriction generated by toxic levels of ergovaline present in endophyte-infected tall fescue seeds.

Trans-rectal color Doppler ultrasonography has been established as a method for obtaining more precise and objective ultrasound measurements. In veterinary medicine, this procedure was first applied to examine cyclic changes in uterine blood flow in cows [10]. It is a non-invasive technique used to examine potential disturbances in uterine blood flow at any stage of gestation [11]. Therefore, our main objective was to use color Doppler ultrasonography to evaluate the occurrence of any alteration in uterine arterial blood flow in pregnant, genotyped beef cows and heifers exposed to endophyte-infected tall fescue seeds and supplemented with RPN. We hypothesize that genetically-tested susceptible control beef cows and heifers will have narrower uterine arteries and decrease blood flow as compared to tolerant cows and heifers that received RPN. The possibility to select tolerant animals to fescue toxicity and supplement them with RPN could mitigate the economic losses that beef producers from the South East of the United States are currently facing.

\section{Materials and Methods}

All procedures for this study were conducted in accordance with a protocol approved by the Auburn University Institutional Animal Care and Use Committee (IACUC) protocol \# 2019-3484. Hair samples were collected from a total of 153 Angus $\times$ Simmental cows and 53 replacement heifers from the Alabama Agricultural
Experiment Station Black Belt Research and Extension Center (Marion Junction, AL) by pulling approximately 2030 hairs from the animal's tail switch, making sure that hair roots were present in the sample. Tolerant and susceptible animals were selected based on information obtained from a genetic test for tolerance to fescue toxicity (Agbotanica, LLC, Columbia, MO). This genetic test provides a tolerance index and results are usually presented to cattle producers in a six-point star rating scale for most susceptible animals (zero stars) or most tolerant animals (five stars). After receiving the results from the genetic test, a total of 28 pregnant animals (i.e., beef cows and heifers) between 6 and 7 months of gestation were selected for the study and separated into two groups of 14 animals tolerant to fescue toxicity (Star rating $=4$ and 5 stars) and 14 animals susceptible to fescue toxicity (Star rating $=0$ and 1 star). This research study is considered a pilot study. The results presented here belong to a broader study whose main objective was to carry out transcriptome studies in the offspring's liver. Therefore, the sample size used in this study was established based on a power analysis contemplating this type of analysis.

The two groups were transported to the Auburn University Beef Cattle Evaluation Center (Auburn, AL) for the RPN supplementation phase of this trial. Within these two groups, seven randomly selected animals received supplemental RPN (AnevisTM, QualiTech, Inc., Chaska, MN) and seven animals received a control diet without RPN. Therefore, there were four different groups: susceptible control (SC), susceptible niacin (SN), tolerant control (TC) and tolerant niacin (TN) (Figure 1). Treatments SC, SN and TN consisted of four heifers and three cows and, TC group was represented by five heifers and two cows. Ideally, animals of similar age should be used in research studies, but we did not count with enough heifers genotyped as susceptible or tolerant to fescue toxicity; therefore, we added cows pregnant with their second calf to the study.

Rumen-protected niacin was top-dressed in the RPNsupplemented diet, using manufacturer's recommended maximum dose of $6 \mathrm{~g} / \mathrm{hd} /$ day. The supplemental diet consisted of ground corn and soybean meal pellets (50:50) mixed with endophyte-infected tall fescue seeds and $6 \%$ molasses. The amount of fescue seeds provided was established based on the ergovaline concentration. Ergovaline concentration in fescue seeds was $5,000 \mathrm{ppb}$ on a DM basis, as measured by HPLC (detection limit $=25 \mathrm{ppb}$ ) [12] at the Veterinary Medical Diagnostic Laboratory of the University of Missouri. The daily dose of ergovaline required to produce characteristic signs of fescue toxicity in beef cattle range from $10 \mu \mathrm{g} / \mathrm{kg} \mathrm{BW} /$ day [13] to $20 \mu \mathrm{g} / \mathrm{kg} \mathrm{BW} /$ day [14]. Therefore, a maximum ergovaline concentration of $20 \mu \mathrm{g} / \mathrm{kg}$ of BW/day was provided through toxic fescue 


\section{Open Access Journal of Veterinary Science \& Research}

seed supplementation. Cows and heifers were trained to a Calan gate system (Northwood, $\mathrm{NH}$ ) to ensure a daily supplementation of 6 grams of RPN, which allowed use of the individual cow/heifer as the experimental unit. In order to have a fall-calving season starting August until late October 2019, animals were bred from November 2018 to January
2019. Animals began receiving RPN supplementation when they were on average 6 months pregnant, and received RPN supplementation for approximately 30 days. They returned to Black Belt Research and Extension Center in August 2019, one month before the expected calving date of the animals that were bred by AI in November 2018.

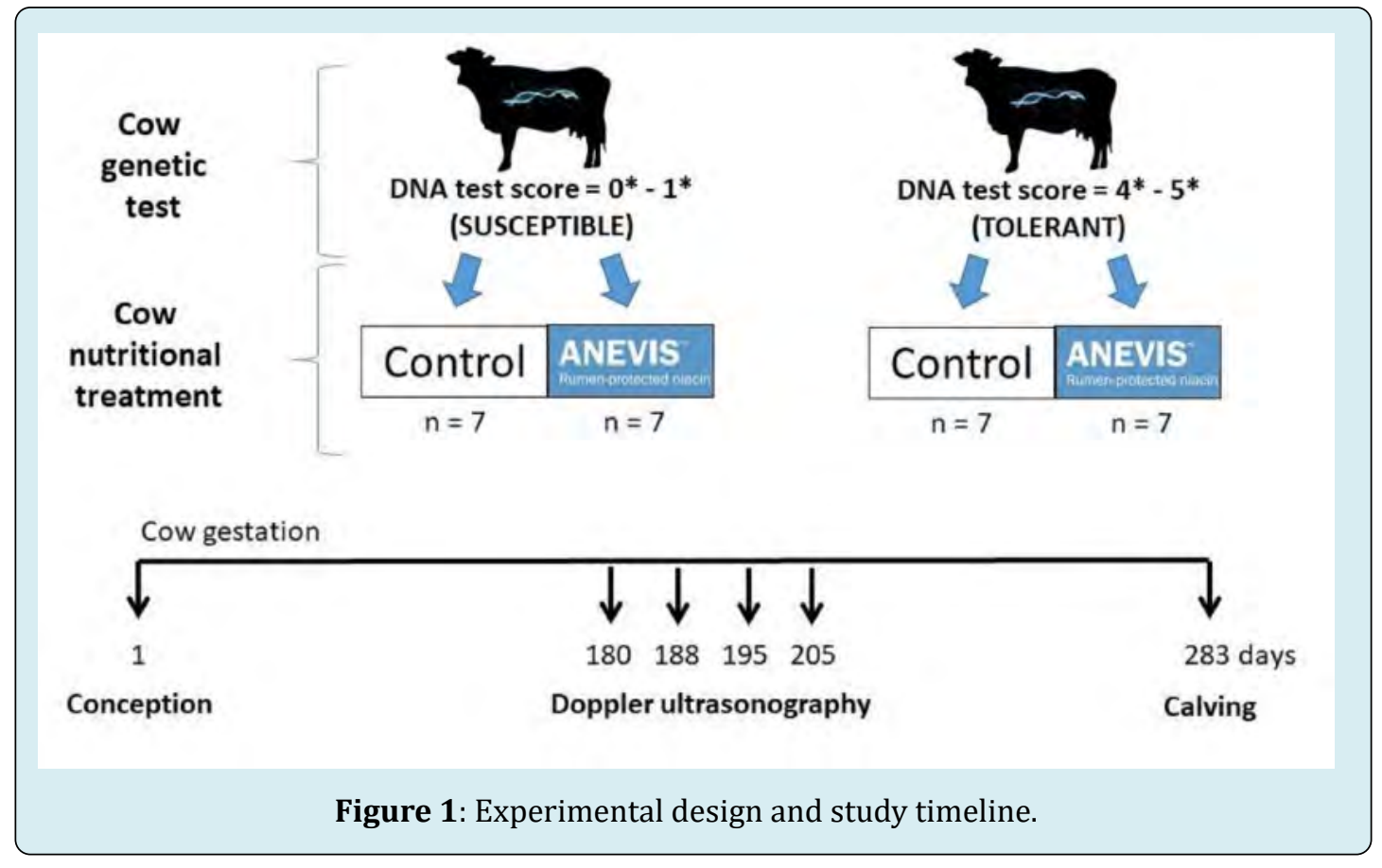

Doppler ultrasound measurements were performed by a single operator using a SonoScape X5 digital color Doppler ultrasound system (SonoScape Medical Corp., Guangdong, China) equipped with an intracavitary $16.0-4-\mathrm{MHz}$ linear transducer (L741V) adapted for trans-rectal examination in large domestic animals. All observations started at 06:00 $\mathrm{h}$ and the cows and heifers were properly restrained. This study was performed when cows and heifers were in midgestation in the month of July. During summer months, there is a higher chance to detect fescue toxicity in cows grazing endophyte-infected tall fescue grass. We only considered the mid-gestation period for this study because it coincides with the time of highest probability of developing fescue toxicity. Doppler ultrasound measurements were collected when cows and heifers were on average 180, 188, 195 and 205 days pregnant (Figure 1). Observations lasted approximately $30 \mathrm{~min}$ for each cow. The uterine arteries ipsilateral and contralateral to the conceptus were scanned weekly during the 30-day RPN supplementation period. The uterine artery was examined using a method previously described $[11,15]$. In brief, the uterine artery was identified within the mesometrium near its origin at the rudimentary umbilical artery and near the external iliac artery. At this location, uterine blood flow spectral tracing was obtained using pulsed wave Doppler by placing the Doppler gate over the uterine artery, adjusted to the diameter of the vessel and angle corrected. B mode ultrasound images were obtained with the same machine to provide information on anatomical structure of soft tissue. The height, width, diameter and circumference were the parameters evaluated in middle uterine arteries. Circumference is presented in two forms, as tracing of the arteries in the Doppler machine and through the calculation of the circumference using $\pi \times$ diameter, or $2 \pi r$ (Table 1). To optimize ultrasound image texture, a dynamic range (DR) of 170 was used and $\mu$ Scan $(\mu S)$ equal to 2 was used to improve the image quality. Finally, the option power (PWR) was used at $100 \%$ to have the maximum ultrasound acoustic power produced by the probe in the $\mathrm{B}$ mode. Uterine blood flow was measured using pulsed wave Doppler (PW) mode. Doppler PW mode measures velocity in a sample volume and displays the information in a spectral trace with audio output. The following variables were determined: height, width, peak systolic velocity (PS), end diastolic velocity (ED) and resistivity index (RI). The RI was calculated using the formula: RI = [(PS-ED)/PS]. 


\section{Open Access Journal of Veterinary Science \& Research}

\begin{tabular}{|c|c|c|c|c|c|c|c|c|c|c|c|}
\hline Variable & Height & Width & $\begin{array}{c}\text { Circ. } \\
\text { (traced) }\end{array}$ & $\begin{array}{c}\text { Radius } \\
\text { (height) }\end{array}$ & $\begin{array}{c}\text { Circ. } \\
\text { (height) }\end{array}$ & $\begin{array}{c}\text { Radius } \\
\text { (width) }\end{array}$ & $\begin{array}{c}\text { Circ. } \\
\text { (width) }\end{array}$ & PS & ED & RI & Gestation \\
\hline Height & 1 & & & & & & & & & & \\
\hline Width & $0.60^{*}$ & 1 & & & & & & & & & \\
\hline Circ. (traced) & $0.89^{*}$ & $0.87^{*}$ & 1 & & & & & & & & \\
\hline Radius (height) & $1^{*}$ & $0.60^{*}$ & $0.89^{*}$ & 1 & & & & & & & \\
\hline Circ. (height) & $1^{*}$ & $0.60^{*}$ & $0.89^{*}$ & $1^{*}$ & 1 & & & & & & \\
\hline Radius (width) & $0.60^{*}$ & $1^{*}$ & $0.87^{*}$ & $0.60^{*}$ & $0.60^{*}$ & 1 & & & & & \\
\hline Circ. (width) & $0.60^{*}$ & $1^{*}$ & $0.87^{*}$ & $0.60^{*}$ & $0.60^{*}$ & $1^{*}$ & 1 & & & & \\
\hline PS & $0.21^{*}$ & $0.17^{* *}$ & $0.24^{*}$ & $0.21^{*}$ & $0.21^{*}$ & $0.17^{* *}$ & $0.17^{* *}$ & 1 & & & \\
\hline ED & $0.13^{* * *}$ & $0.14^{* *}$ & $0.20^{*}$ & $0.13^{* * *}$ & $0.13^{* * *}$ & $0.14^{* *}$ & $0.13^{* *}$ & $0.59^{*}$ & 1 & & \\
\hline RI & -0.04 & -0.01 & -0.02 & -0.04 & -0.04 & -0.01 & -0.01 & 0.02 & $0.58^{*}$ & 1 & \\
\hline Gestation & $0.19^{*}$ & $0.19^{* *}$ & $0.20^{*}$ & $0.19^{*}$ & $0.19^{*}$ & $0.18^{* *}$ & $0.19^{* *}$ & 0.03 & 0.03 & 0.04 & 1 \\
\hline
\end{tabular}

Table 1: Pearson's rank correlation coefficients between Doppler ultrasonographic parameters in pregnant, genotyped beef cows and heifers supplemented with rumen-protected niacin and exposed to endophyte-infected tall fescue seeds.

Uterine ipsilateral and contralateral arteries height and width, circumference traced manually, circumference width and height, radius height and width, peak systolic velocity (PS), end diastolic velocity (ED) and resistivity index (RI) and gestation length, $\mathrm{n}=224$. Statistically significant differences were declared at $P<0.01$ denoted as $(*), P>0.01$ and $<0.05$ $\left(^{* *}\right)$ and tendencies at $P>0.05$ and $<0.1{ }^{* * *}$ ).

For placentome evaluation, color flow images were used. Color flow imaging adds the color-coded qualitative information in the B-mode image. Color flow imaging is helpful to evaluate the flow, the relevant qualitative information, and flow velocity. Furthermore, we used the "color flow mapping mode" (CFM Mode), which is a color flow imagining technology, which adds the color-coded qualitative information concerning the relative velocity and direction of fluid motion in the B-mode images. A frequency (F) equal to $5 \mathrm{MHz}$ was utilized in order to optimize the penetrability and the sensitivity of the color flow. A color flow gain (GN) between 120 and 165 was used to optimize color flow continuity with less noise interference. A low level of wall filter (WF) was used to filter the low-frequency noise from tissues, such as the vascular wall. Furthermore, a pulse repetition frequency (PRF) of $3 \mathrm{MHz}$ was used to adjust the velocity scale. Diameter, circumference, and blood flow were recorded in the placentomes and in the uterine arterial walls. The device calculated all indices automatically and they were saved on a USB removable disk. Changes over time in the mentioned parameters were compared between the treatment groups at 4 different time points.

\section{Statistical Analysis}

Data were analyzed with linear mixed models using the
GLIMMIX procedure of SAS (ver. 9.4; SAS Institute Inc., Cary, NC). Fixed effects in the statistical model for each response variable analyzed (e.g., uterine artery width and height) included genetic test results (susceptible and tolerant), dietary treatment (RPN and control), side (ipsilateral and contralateral), time (four weekly measurements from each cow, with the repeated measurements analyzed using a heterogeneous first-order autoregressive correlation structure), and their interactions. Animal category (i.e., cow or heifer) and gestation length were included as covariates. Significant differences were declared at $P<0.05$.

The full statistical model used was: $\mathrm{Y}_{\mathrm{ijk} / m n}=\mu+\mathrm{T}_{\mathrm{i}}+\mathrm{D}_{\mathrm{j}}+$ $\mathrm{W}_{\mathrm{k}}+\mathrm{S}_{1}+\mathrm{C}_{\mathrm{m}}+\mathrm{G}_{\mathrm{n}}+(\mathrm{T} \times \mathrm{D})_{\mathrm{ij}}+(\mathrm{T} \times \mathrm{W})_{\mathrm{jk}}+(\mathrm{T} \times \mathrm{S})_{\mathrm{il}}+(\mathrm{D} \times \mathrm{W})_{\mathrm{jk}}+$ $(\mathrm{D} \times \mathrm{S})_{\mathrm{j} 1}+(\mathrm{W} \times \mathrm{S})_{\mathrm{kl}}+(\mathrm{T} \times \mathrm{D} \times \mathrm{W})_{\mathrm{ijk}}+(\mathrm{T} \times \mathrm{D} \times \mathrm{S})_{\mathrm{ij} 1}+(\mathrm{T} \times \mathrm{W} \times \mathrm{S})$ ${ }_{\mathrm{ikl}}+(\mathrm{D} \times \mathrm{W} \times \mathrm{S})_{\mathrm{jkl}}+(\mathrm{T} \times \mathrm{D} \times \mathrm{W} \times \mathrm{S})_{\mathrm{ijkl}}+\varepsilon_{\mathrm{ijk} \mathrm{lm} n} ;$ where, $\mathrm{Y}_{\mathrm{ijkl}}$ is the variable of interest; $\mu$ is the overall mean; $T_{i}$ is the fixed effect of time (4 levels); $\mathrm{D}_{\mathrm{i}}$ is the fixed effect of the genetic test (2 levels); $\mathrm{W}_{\mathrm{k}}$ is the fixed effect of cow's RPN supplementation (2 levels); $S_{1}$ is the side (2 levels); $C_{m}$ is the category (2 levels); $\mathrm{G}_{\mathrm{n}}$ is the gestation length; $\mathrm{T} \times \mathrm{D}, \mathrm{T} \times \mathrm{W}, \mathrm{T} \times \mathrm{S}, \mathrm{D} \times \mathrm{W}, \mathrm{D} \times \mathrm{S}$, and $\mathrm{W} \times \mathrm{S}$ are the second-order interactions of the main effects; $\mathrm{T}$ $\times \mathrm{D} \times \mathrm{W}, \mathrm{T} \times \mathrm{D} \times \mathrm{S}, \mathrm{T} \times \mathrm{W} \times \mathrm{S}$, and $\mathrm{D} \times \mathrm{W} \times \mathrm{S}$ are the third-order interactions of the main effects; ; $\mathrm{T} \times \mathrm{D} \times \mathrm{W} \times \mathrm{S}$ is the fourthorder interaction of the main effects; and $\varepsilon_{\mathrm{ijk} k \mathrm{~m}}$ is the random error $\left(0, \sigma_{\mathrm{e}}^{2}\right)$ associated with $\mathrm{Y}_{\mathrm{ij \textrm {k }} \mathrm{m} n}$. Preliminary analyses indicated that none of the interactions were significant $(P>$ 0.10 ) in models for any of the variables of interest; therefore, models for all variables of interest were reduced to maineffects-only models: $\mathrm{Y}_{\mathrm{ijk} k \mathrm{mn}}=\mu+\mathrm{T}_{\mathrm{i}}+\mathrm{D}_{\mathrm{j}}+\mathrm{W}_{\mathrm{k}}+\mathrm{S}_{1}+\mathrm{C}_{\mathrm{m}}+\mathrm{G}_{\mathrm{n}}$ $+\varepsilon_{\mathrm{ijklmn}}$. Comparisons between least-squares means of factor levels were performed using 2-sided t-tests, with p-values for multiple comparisons adjusted using the Shaffer-Simulated method. Finally, correlation analysis was performed using 


\section{Open Access Journal of Veterinary Science \& Research}

the CORR procedure of SAS.

\section{Results}

\section{Animals}

Overall, animals under study were in good health conditions with no clinical signs of fescue toxicity. Nevertheless, excessive salivation was observed in some of the dams. More information about the animals under study is presented in a complementary publication. Animals had a good adaptation to the diet mixed with fescue seeds due to the addition of molasses, which increased palatability significantly.

\section{Blood Flow in the Uterine Arteries}

There were not significant four- or third-order interaction between time, genetic and nutritional treatment and side for any of the variables analyzed (data not shown). We expected to observe significant interactions between side and treatments applied due to the presence of the fetus in the ipsilateral uterine horn which usually has a greater blood flow than the contralateral uterine artery [16], but this was not observed in our study. However, there was a category effect (i.e., heifer or cow) and a time effect for all the variables analyzed $(P<0.01)$. Resistivity index did not have any significant genetic or nutritional effect but values were greater for all treatments as compared to reference values for pregnant cows' not exposed to ergovaline in fescue seeds (Horizontal lines in Figure 2).

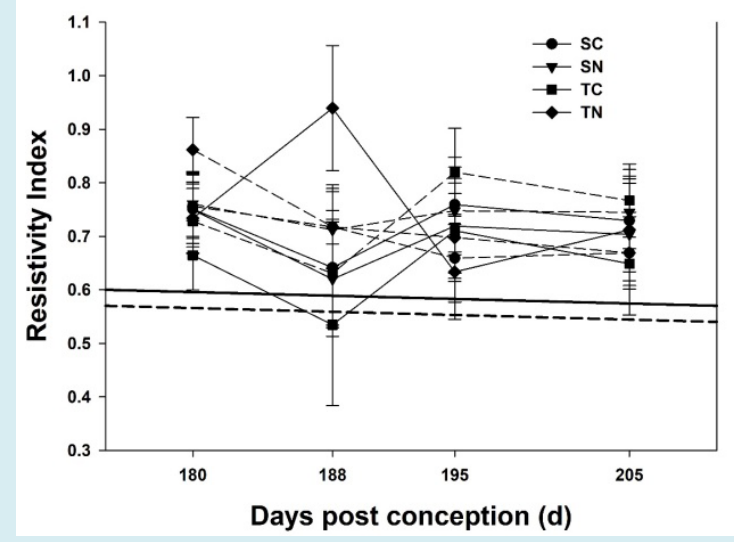

Figure 2: Resistivity index measured by Doppler ultrasonography on days post conception 180,188, 195 and 205 in the ipsilateral and contralateral uterine arteries in pregnant, genotyped beef cows and heifers supplemented with rumen-protected niacin and exposed to endophyteinfected tall fescue seeds.
Treatments: Susceptible Control (SC); Susceptible Niacin (SN); Tolerant Control (TC) and Tolerant Niacin (TN). Dashed lines represent contralateral side and straight lines represent ipsilateral side. Straight and dashed descendent lines across graph represent a typical RI value for a pregnant cow non expose to ergovaline for its ipsilateral and contralateral uterine artery respectively (Data obtained from (Bollwein, et al. 2002). Statistically significant differences were declared at $P<0.05$ and tendencies at $P>0.05$ and $<0.1$.

There were positive correlations among all the Doppler parameters related to uterine arterial area $(P<0.01)$. Resistivity index did not have significant correlations, except for the correlation between RI and ED $(P<0.01)$. Furthermore, there were significant positive correlations between PS and ED and all the Doppler parameters related to uterine arterial area $(P<0.01)$. A strong positive correlation was observed between ED and PS and ED and RI $(P<0.01)$. Correlations between ED and uterine area measurements had tendencies for being slightly positive $(P=0.06)$. Finally, gestation length had significant correlations only for uterine area Doppler parameters $(P<0.01)$ but not for Doppler uterine blood flow parameters $(P>0.05)$ (Table 1$)$.

\section{Placentome's Evaluation}

Several Doppler placentome images show inflammation, calcification, and/or fibrotic areas. The image of the placentome in Fig. 5 has small areas of fibrosis along the fetal (outside) border. These findings are consistent with ergovaline effects on the placenta [17]. Knowing that each placentome have different hemodynamic characteristics, placentome's blood flow was not measured due to the lack of certainty of being assessing the same placentome each time using the rectal probe.

\section{Discussion}

Differences between ipsilateral and contralateral uterine arteries are related to a single pregnancy, which leads to differences in blood supply in each horn. In species where twins are common, like ewes, no differences between sides are expected with similar blood supply in each horn [18]. We did not detect twin pregnancies. Furthermore, we did not observe differences in any Doppler parameter when comparing ipsilateral and contralateral uterine horns.

A progressive decrease in uterine arterial height was observed throughout the study (Figure 3A). However, an opposite pattern was observed in all Doppler parameters related to blood vessels area (Figure 3B). Administration of toxic fescue seeds in the diet of all animals under study could be the reason for the decrease in uterine arterial height. In 
a previous study, endophyte-infected tall fescue exposure of pregnant animals resulted in marked medial proliferation of placental vessels with subsequent placental thickening [19].
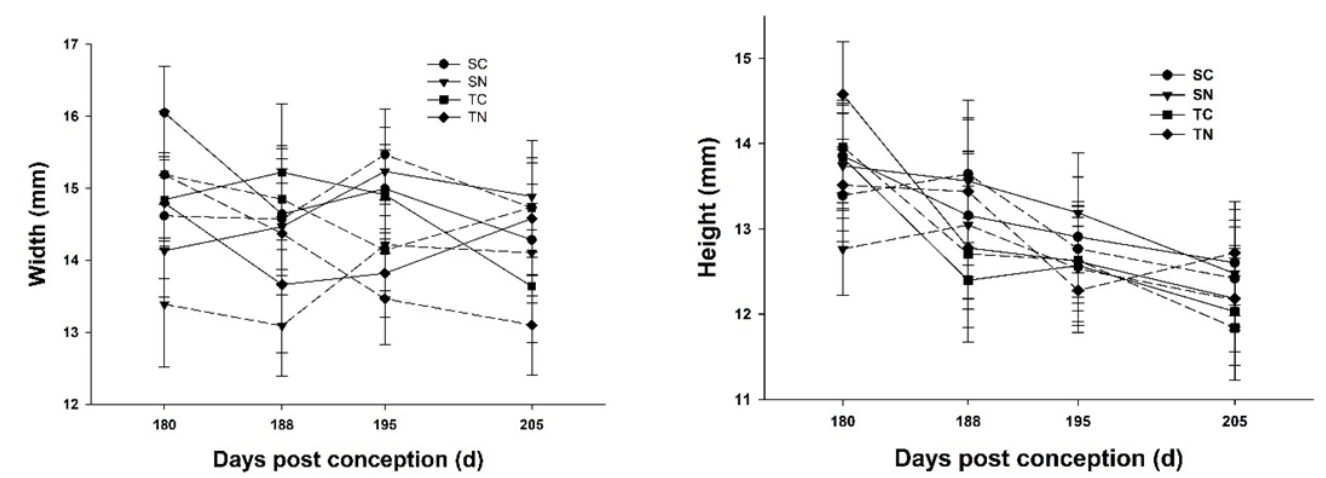

Figure 3: Doppler ultra-sonographic parameters measured on days post conception 180, 188 , 195 and 205 in the ipsilateral and contralateral uterine arteries in pregnant, genotyped beef cows and heifers supplemented with rumen-protected niacin and exposed to endophyte-infected tall fescue seeds.

Treatments: Susceptible Control (SC); Susceptible Niacin (SN); Tolerant Control (TC); and Tolerant Niacin (TN). Dashed lines represent contralateral side and straight lines represent ipsilateral side. Statistically significant differences were declared at $P<0.05$ and tendencies at $P>0.05$ and $<0.1$

Measurements of blood flow volume usually show an exponential increase during pregnancy because the fetus is growing and the increased metabolic requirements of the fetus are met by a commensurate increase in uterine blood flow [20]. Our data did not show this trend (Figure 4). However, there was a significant positive correlation between gestation length and uterine blood vessel height (Table 1).

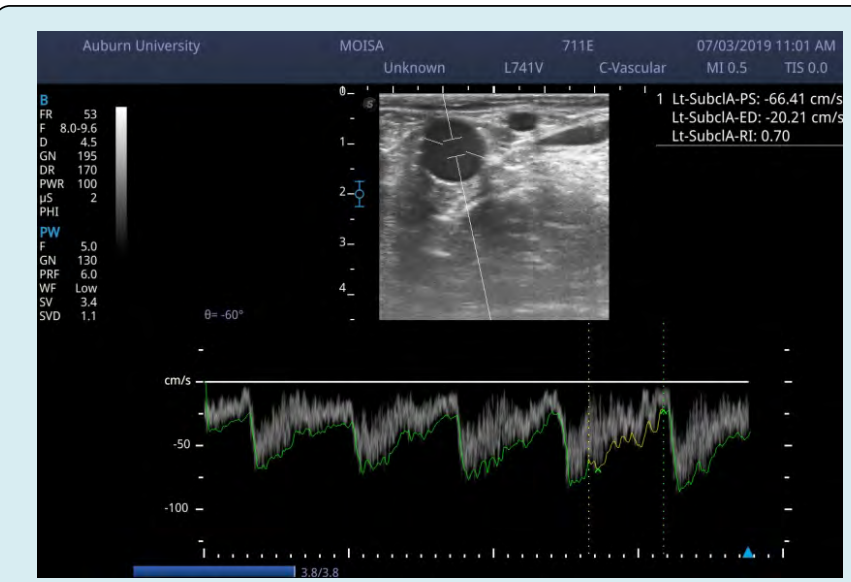

Figure 4: Representative sonogram showing the variation of blood flow indices measured from the uterine artery in pregnant, genotyped beef cows supplemented with rumenprotected niacin and exposed to endophyte-infected tall fescue seeds.

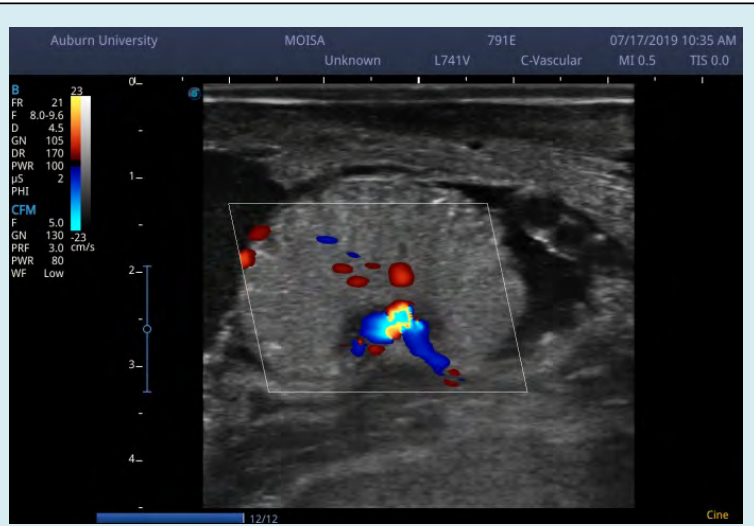

Figure 5: Representative sonogram showing a placentome in a pregnant, genotyped beef cow supplemented with rumen-protected niacin and exposed to endophyteinfected tall fescue seeds.

The RI is the negative relationship between the extent of resistance in the tissues and vascular perfusion; the greater the RI, the lesser the perfusion. The lesser RI is interpreted as an increased blood flow to the reproductive organs [21]. The RI increases if the proximal conditions remain constant and the distal vascular bed constricts. Conversely, a low value for the RI indicates decreased impedance of blood flow in the distal vasculature [22]. In previous studies, the RI decreased significantly in the first 8 months of pregnancy [11] and remained at a relatively constant level thereafter [23]. In the present study, cows and heifers were on average approximately 6 months pregnant at the beginning of Doppler measurements; however, no significant decrease in RI was observed (Figure 3), which may also be a result of all animals on the study were consuming toxic fescue seeds and, 


\section{Open Access Journal of Veterinary Science \& Research}

some effect on the RI. Consumption of feeds with ergovaline is known to have altered uterofetoplacental progestagen metabolism leading to alterations in the placenta [17]. Chorioallantoic changes following fescue toxicity include edema, smooth muscle hyperplasia, mucoid degeneration of vessels and fibrosis [17]. These changes occur following anoxia due to vasoconstriction. Lipomatosis, also called fat necrosis, is reported to occur as a result of cows consuming ergovaline feed stuffs [17]. The lipolytic process can result from vasoconstriction, directly or secondarily to a febrile condition, or increased oxidative stress which all occur with fescue toxicity [17]. The lipolytic process has the ability to affect the placentome, the site of maternal-fetal nutrient exchange in ruminant animals, and can lead to inflammation, fibrosis and calcification of the structure with a resultant reduction of blood flow to the fetus and with no significant decrease in RI. Additionally, a previous study evaluating the response of uterine arteries and umbilical arteries to ergovaline, it was found that following consumption of ergovaline in ewes, the uterine arteries were not responsive to the exposure but the umbilical arteries were responsive $(P<0.05)$ [24]. These findings indicate that maternal blood supply to the placenta appears protected from negative effects of ergot alkaloids; however, umbilical vasculature is not, and this could and does adversely influence fetal growth.

Niacin generates vasodilation [25], producing the opposite effect of the ergovaline alkaloid present in endophyte-infected tall fescue, which is a vasoconstrictor $[26,27]$. The alkaloid ergovaline inhibits physiological peripheral vasodilation, which is an important mechanism for temperature homeostasis in cattle. Beef cattle under fescue toxicity usually experience heat stress [28]. In our study, supplementation of RPN at mid-gestation did not exert its expected vasodilator effect in uterine arteries. It might be because the uterine arteries were not as affected by the ergovaline so the RPN did not have a measurable effect. Therefore, there were no improvements in uterine perfusion in the cows and heifers under this study. Further studies with larger numbers of animals per group and further evaluation of umbilical artery and placentomes' blood flow are warranted to clarify the effect of RPN on pregnant, genotyped beef cows exposed to endophyte-infected tall fescue seeds.

\section{Conclusion}

The use of rumen-protected niacin supplementation in mid-gestation on genotyped beef cows and heifers tested to be tolerant or susceptible to fescue toxicity did not demonstrate any significant effects in uterine blood flow parameters measured using Doppler ultrasonography.

Conflicts of Interest: The authors declare no conflict of interest.

\section{Acknowledgements}

We thank Dr. Paul Dyce for suggesting Dr. Julie Gard Schnuelle as the expert veterinarian capable of obtaining the Doppler ultrasound data for this study. We thank Jack Garrett, Director of Research and Technical Support (Animal Nutrition division) from QualiTech, Inc., who collaborated donating the rumen-protected niacin $\left(\mathrm{ANEVIS}^{\mathrm{TM}}\right.$ ) for this research project. Finally, the authors thank Robert Britton and George Richburg for their extraordinary collaboration during the course of this study.

\section{Funding}

This work was funded by the USDA National Institute of Food and Agriculture, Hatch program -Project No. ALA013-1-19058 , 2019 Alabama Agricultural Experiment Station - Production Agriculture Research funding program - Production Agriculture Research Funding program (AAESPAR 2019), Alabama Cattlemen's Association and QualiTech, Inc.

\section{References}

1. Young CA, Charlton ND, Takach JE, Swoboda GA, Trammell MA, et al. (2014) Characterization of Epichloe coenophiala within the US: are all tall fescue endophytes created equal? Frontiers in Chemistry 2: 95.

2. Leuchtmann A, Bacon CW, Schardl CL, White JF, Tadych $M$ (2014) Nomenclatural realignment of Neotyphodium species with genus Epichloe. Mycologia 106(2): 202215.

3. Bacon CW, Porter JK, Robbins JD, Luttrell ES (1977) Epichloe-Typhina from Toxic Tall Fescue Grasses. Applied and Environmental Microbiology 34(5): 576-581.

4. Hoveland CS, Haaland RL, King CC, Anthony WB, Clark EM, et al. (1980) Association of Epichloe-Typhina Fungus and Steer Performance on Tall Fescue Pasture. Agronomy Journal 72(6): 1064-1065.

5. Belesky DP, Stuedemann JA, Plattner RD, Wilkinson SR (1988) Ergopeptine Alkaloids in Grazed Tall Fescue. Agronomy Journal 80(2): 209-212.

6. Kallenbach RL (2015) BILL E. KUNKLE INTERDISCIPLINARY BEEF SYMPOSIUM: Coping with tall fescue toxicosis: Solutions and realities. Journal of Animal Science 93(12): 5487-5495.

7. Klotz JL, McDowell KJ (2017) Tall fescue ergot alkaloids are vasoactive in equine vasculature. Journal of Animal Science 95(11): 5151-5160. 


\section{Open Access Journal of Veterinary Science \& Research}

8. Klotz JL, Aiken GE, Bussard JR, Foote AP, Harmon DL, et al. (2016) Vasoactivity and Vasoconstriction Changes in Cattle Related to Time off Toxic Endophyte-Infected Tall Fescue. Toxins (Basel) 8(10): 271.

9. Poole DH, Lyons SE, Poole RK, Poore MH (2018) Ergot alkaloids induce vasoconstriction of bovine uterine and ovarian blood vessels. J Anim Sci 96(11): 4812-4822.

10. Bollwein H, Meyer HH, Maierl J, Weber F, Baumgartner U, et al. (2000) Transrectal Doppler sonography of uterine blood flow. Theriogenology 53(8): 1541-1552.

11. Bollwein H, Baumgartner U, Stolla R (2002) Transrectal Doppler sonography of uterine blood flow in cows during pregnancy. Theriogenology 57(8): 2053-2061.

12. Rottinghaus GE, Schultz LM, Ross PF, Hill NS (1993) An HPLC method for the detection of ergot in ground and pelleted feeds. J Vet Diagn Invest 5(2): 242-247.

13. Spiers DE, Eichen PA, Leonard MJ, Wax LE, Rottinghaus GE, et al. (2004) Benefit of dietary seaweed (Ascophyllum nodosum) extract in reducing heat strain and fescue toxicosis: a comparative evaluation. Journal of Thermal Biology 29(7-8): 753-757.

14. Holtcamp AJ, Sukumaran AT, Schnedler AE, McClenton BJ, Kunze E, et al. (2019) Effects of feeding endophyteinfected tall fescue seeds to stocker Angus steers on retail quality attributes of beef strip steaks. Meat Science 149: 31-39.

15. Honnens A, Niemann H, Paul V, Meyer HH, Bollwein $H$ (2008) Doppler sonography of the uterine arteries during a superovulatory regime in cattle. Uterine blood flow in superovulated cattle. Theriogenology 70(5): 859-867.

16. Konje JC, Kaufmann P, Bell SC, Taylor DJ (2001) A longitudinal study of quantitative uterine blood flow with the use of color power angiography in appropriate for gestational age pregnancies. American Journal of Obstetrics and Gynecology 185(3): 608-613.

17. Casteel SW (2007) Reproductive Toxicants. In: Younquist RS, threlfaa W, (Eds.), Current Therapy in Large Animal Theriogenology, $2^{\text {nd }}($ Edn.), Elsevier, pp: 420-427.

18. Beltrame RT, Covre C, Littig LB, Martins AB, Quirino CR, et al. (2017) Transrectal Doppler sonography of uterine blood flow in ewes during pregnancy. Theriogenology 91: 55-61.

19. Haschek WM, Wallig MA, Rousseaux C (2010) Fundamentals of Toxicologic Pathology. In: Fundamentals of Toxicologic Pathology, 2ne (Edn.), Elsevier, pp: 360.

20. Herzog K, Bollwein H (2007) Application of Doppler ultrasonography in cattle reproduction. Reprod Domest Anim 42(2): 51-58.

21. Bollwein H, Heppelmann M, Luttgenau J (2016) Ultrasonographic Doppler Use for Female Reproduction Management. Veterinary Clinics of North America-Food Animal Practice 32(1): 149-169.

22. Oglat AA, Matjafri MZ, Suardi N, Oqlat MA, Abdelrahman MA, et al. (2018) A Review of Medical Doppler Ultrasonography of Blood Flow in General and Especially in Common Carotid Artery. J Med Ultrasound 26(1): 3-13.

23. Kim-Egloff C, Hassig M, Bruckmaier R, Bleul U (2016) Doppler sonographic examination of uterine and placental perfusion in cows in the last month of gestation and effects of epidural anesthesia and isoxsuprine. Theriogenology 85(5): 986-998.

24. Klotz JL, Britt JL, Miller MF, Snider MA, Aiken GE, et al. (2019) Ergot alkaloid exposure during gestation alters: II. Uterine and umbilical artery vasoactivity. Journal of Animal Science 97(4): 1891-1902.

25. Kamanna VS, Ganji SH, Kashyap ML (2009) The mechanism and mitigation of niacin-induced flushing. International Journal of Clinical Practice 63(9): 13691377.

26. Strickland JR, Cross DL, Birrenkott GP, Grimes LW (1994) Effect of Ergovaline, Loline, and Dopamine Antagonists on Rat Pituitary Cell Prolactin-Release in-Vitro. American Journal of Veterinary Research 55(5): 716-721.

27. Klotz JL, Bush LP, Smith DL, Shafer WD, Smith LL, et al. (2007) Ergovaline-induced vasoconstriction in an isolated bovine lateral saphenous vein bioassay. Journal of Animal Science 85(9): 2330-2336.

28. Kishore DK, Eichen PA, Spiers DE (2012) Adaptive responses to fescue toxicosis under thermoneutral and heat stress conditions. Journal of Thermal Biology 37(4): 323-329. 